\title{
Structure and Antibacterial Activity of Bi-cyclohexanone Pentaerythritol Ketal
}

\author{
Li HUANG* \\ School of Nursing, Xi'an Medical University, Xi'an 710068, China \\ *tougao88@163.com
}

Keywords: Cyclohexanone pentaerythritol ketal, X-ray structure, antibacterial activity

\begin{abstract}
Cyclohexanone pentaerythritol ketal was synthesized from cyclohexanone and pentaerythritol by condensation using $\mathrm{NaHSO}_{4}$ as catalyst and characterized by NMR and MS spectrum. Furthermore, the structure of the tile compound was confirmed by single-crystal X-ray diffraction. It crystallizes in orthorhombic space group, $\mathrm{P} 21$, with a unit cell dimensions of a = 11.1214(9) $\AA, b=13.9216(6) \AA$ and $c=11.6658(10) \AA$. In the crystal, there are two independent molecules with different conformation, varying both in bond lengths and angles. In each molecular, there are four six-membered cycles, two cyclohexyl groups and two 1,3-dioxane groups. The four six-membered cycles all display a typical stable boat conformation. The stacking interaction is responsible for the crystal's 1-D supra-molecular structure. The thermal gravimetric analysis (TGA) indicates the title compound is stable below $200^{\circ} \mathrm{C}$, and the remaining weight ratio is less than $9 \%$ above $300^{\circ} \mathrm{C}$. This compound was evaluated for their in vitro antimicrobial activity against six bacteria (S. aureus, S. epidermidis, M. luteus, E. coli, K. pneumoniae, A. fumigatus). It some anti-inflammatory activity against the tested bacteria and the inhibition is depending on the concentration.
\end{abstract}

\section{Introduction}

Acetals/ketals are the important compounds or intermediates in the steroid chemistry and synthetic carbohydrate [1,2]. In the synthesis, the acetals/ketals always need protection by 1,2- or 1,3-diols due to the high activity, which is commonly used in carbohydrate chemistry. Besides, the acetals/ketals are used as intermediates and/or end products, in the phyto pharmaceutical, fragrances and lacquers industries $[3,4]$. They also have been used as solvents in many fields, such as cosmetics, detergent and lacquer industries [5], fragrance industries [6], pharmaceuticals [7], synthesis of enantiomerical compounds and polymer [8,9], beverage additives and food [10]. Acetals and its derivatives have also been used as additives in motor lubricating oils, and water based fluids of drilling petroleum operations [11]. [2,2-bis(hydroxymethyl)propane-1,3-diol], pentaerythritol, is an important building block in thesynthesis of versatile compounds. Pentaerythritol can react with acetals/ketals to produce pentaerythritol acetals, which can be applied as vulcanizers and plasticizers, raw materials for production of valuable resins and lacquers [12]. In this article, we synthesized cyclohexanone pentaerythritol ketal (as shown in Scheme 1), studied its structure by single-crystal X-ray diffraction analysis and screened its antibacterial activity.

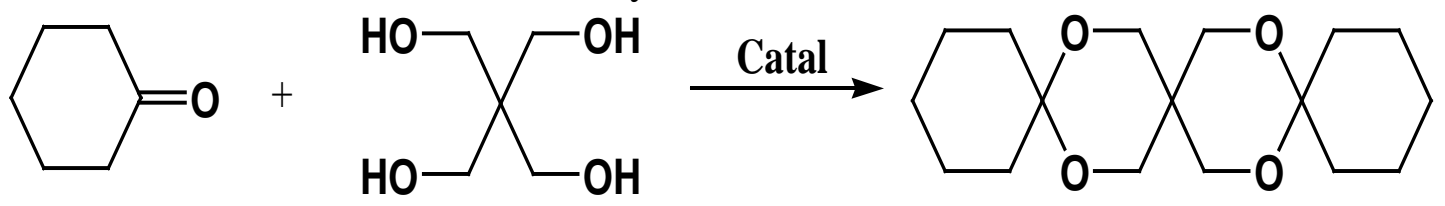

Scheme 1 Synthesis of cyclohexanone pentaerythritol ketal 


\section{Results and Discussion}

\section{Structure}

The stereo structure of cyclohexanone pentaerythritol ketal was corroborated by single-crystal X-ray diffraction analysis. The main experimental data of the title compound is displayed in Table 1 . The molecular structure is described in Fig. 1, and the packing of the compounds is depicted in Fig. 2, which were drawn with ORTEP-3. The structure of the title compound confirmed by X-ray is consistent with its structure determined by NMR and MS spectra data. All the geometric parameters of the title crystal are in the usual ranges. It crystallizes in triclinic space group, $P_{21}$, and the unit cell dimension is: $\mathrm{a}=11.1214(9) \AA \mathrm{,}, \mathrm{b}=13.9216(6) \AA$ and $\mathrm{c}=11.6658(10) \AA$.

Table 1 Experimental Data

\begin{tabular}{ll}
\hline Empirical formula & $\mathrm{C}_{34} \mathrm{H}_{56} \mathrm{O}_{8}$ \\
\hline Formula weight & 592 \\
Temperature & $293(2)$ \\
Wavelength (Mo K $\square$ ) & 0.71088 \\
Crystal system & Monoclinic \\
Space group & $\mathrm{P} 21$ \\
Unit cell dimensions & $11.1214(9), 13.9216(6), 11.6658(10)$ \\
Volume & $1593.8(2)$ \\
$\mathrm{Z}$ & 4 \\
Absorption coefficient & 0.086 \\
F (000) & 654 \\
Crystal size & $0.41 \times 0.32 \times 0.24 \mathrm{~mm}^{3}$ \\
Theta range for data collection & 1.55 to 24.00 \\
( $)^{\circ}$ & \\
Index ranges & $-15 \leq \mathrm{h} \leq 7 ;-18 \leq \mathrm{k} \leq 9 ;-6 \leq \mathrm{l} \leq 15$ \\
Reflections collected & 4504 \\
Independent reflections & 3880 \\
Reflections theta $\left({ }^{\circ}\right)$ & 3.50 to 28.78 \\
Absorption correction & 0.9661 to 0.9834 \\
transmission & \\
Refinement method & Full-matrix least-squares on $\mathrm{F}^{2}$ \\
Data / restraints / parameters & 3880 / $1 / 380$ \\
Goodness-of-fit on F ${ }^{2}$ & 0.927 \\
Final R indices [I $>$ 2s(I)] & $\mathrm{R} 1=0.0657 ;$ wR2 = 0.1447 \\
R indices (all data) & $\mathrm{R} 1=0.0449 ; \mathrm{wR} 2=0.1241$ \\
Refine different density & -0.202 to 0.172 \\
\hline
\end{tabular}

In the crystal, there are two independent molecules with different conformation varying in bond lengths and angles, as shown in Fig. 1 and Table 4. For example, the lengths of the main C-O bonds, C1-O1, C4-O2, C3-O3, and C5-O4 are 1.430, 1.425, 1.429, and $1.421 \AA$ respectively, while, in the other molecular, the lengths of the main C-O bonds, C1'-O1', C4'-O2', C3'-O3', and C5'-O4' are 1.429, 1.417, 1.412, and $1.425 \AA$ respectively. The main angles of $\mathrm{C}-\mathrm{O}-\mathrm{O}$ bonds, $\angle \mathrm{C} 1-\mathrm{O} 1-\mathrm{C} 6$, $\angle \mathrm{C} 4-\mathrm{O} 2-\mathrm{C} 6, \angle \mathrm{C} 3-\mathrm{O} 3-\mathrm{C} 12$, and $\angle \mathrm{C} 5-\mathrm{O} 4-\mathrm{C} 12$, are $114.4,114.5,114.2$, and $113.4^{\circ}$ respectively, while, in the other molecular, the main angles of C'-O'-O' bonds, $\angle \mathrm{C} 1$ '-O1'-C6', $\angle \mathrm{C} 4$ '-O2'-C6', $\angle \mathrm{C}^{\prime}$ '-O3'-C12', and $\angle \mathrm{C} 5$ '-O4'-C12', are $113.4,114.3,115.1$, and $114.4^{\circ}$ respectively. There are three quaternary carbons in each molecular. The bonds length related to $\mathrm{C} 2$ are very similar in the range from $1.518 \AA$ to $1.532 \AA$, and the related angels are from 107.0 to $111.0^{\circ}$, which should be due 
to the symmetry center role of C2. For other two quaternary carbons, C6 and C12, the related bonds length and the angle are in wider ranges.

In each molecular, there are four six-membered cycles, two cyclohexyl groups and two 1,3-dioxane groups. The four six-membered cycles all display the typical stable boat conformations, as shown in Fig. 1. There is no typical hydrogen bond in the two compound crystals for without hydrogen bond donor. As shown in Fig. 2, the stacking interaction is responsible for the crystal's 1-D supra-molecular structure, and the cyclohexyl groups and 1,3-dioxane groups incline to stack respectively. Besides, it is obviously that the two cyclohexyl groups stack in different directions one by one because of the fixed spiro structure.

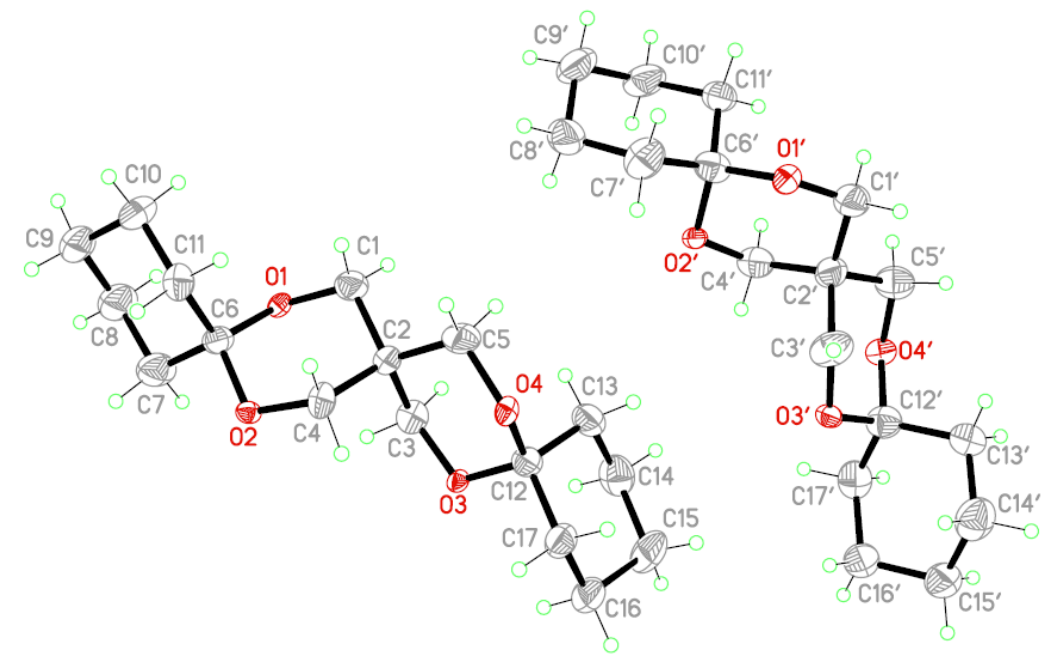

Fig. 1 The molecular structure of cyclohexanone pentaerythritol ketal

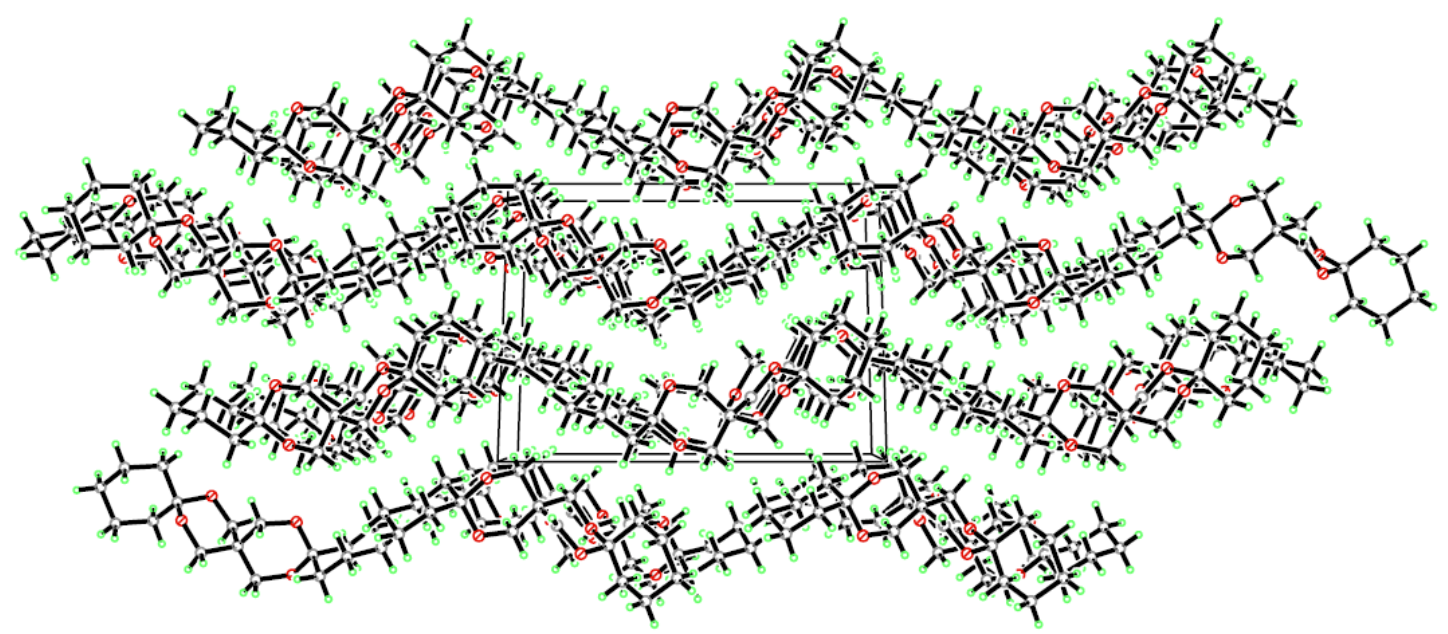

Fig. 2 The $1 \mathrm{D}$ and 2D packing diagram of cyclohexanone pentaerythritol ketal

\section{Thermal Gravimetric Analysis}

The thermal character was studied by thermal gravimetric analysis and the TGA analysis was shown in Fig. 3. The TGA curve indicates that the title compound is stable below $200^{\circ} \mathrm{C}$, and the compound starts to lose weight sharply as the temperature above $200^{\circ} \mathrm{C}$. The first weight loss stage between $30^{\circ} \mathrm{C}$ and $200^{\circ} \mathrm{C}$ is only about $8 \%$, which may correspond to the loss of absorbed solvent. The second weight loss stage is about $83 \%$ between 200 and $300^{\circ} \mathrm{C}$, which should correspond to the decomposition of cyclohexanone pentaerythritol ketal. Above $300^{\circ} \mathrm{C}$, there is less than $9 \%$ remaining, which may be due to the residue of carbon deposit. 


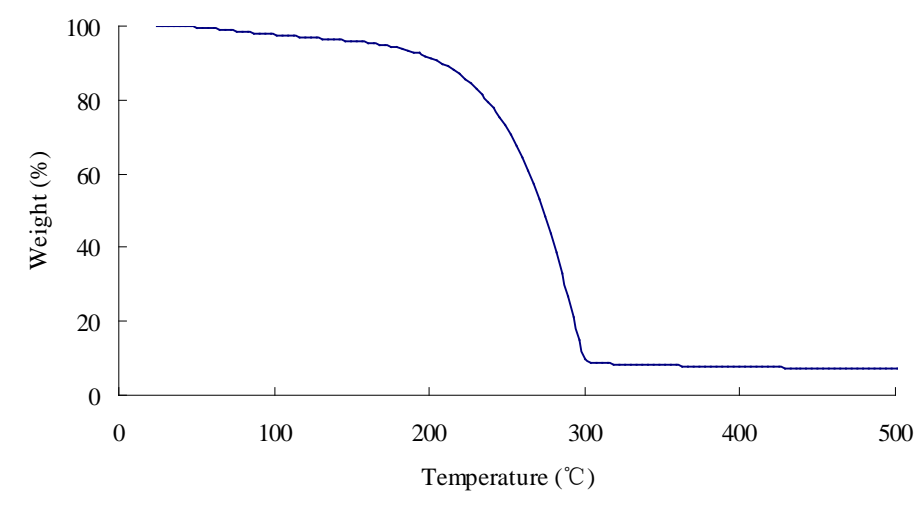

Fig. 3 The TGA curves of cyclohexanone pentaerythritol ketal

\section{Anti-inflammatory Activity}

In the daily sports and fitness (as shown in Fig. 4), there will be some small accidents, such as sprains, contusions, bleeding, etc., especially when injury wound contacts with the ground infiltrating some bacteria. Young people are generally infected gram-positive bacteria, and the physical weak elderly are inclined to be infected with gram-negative bacteria.
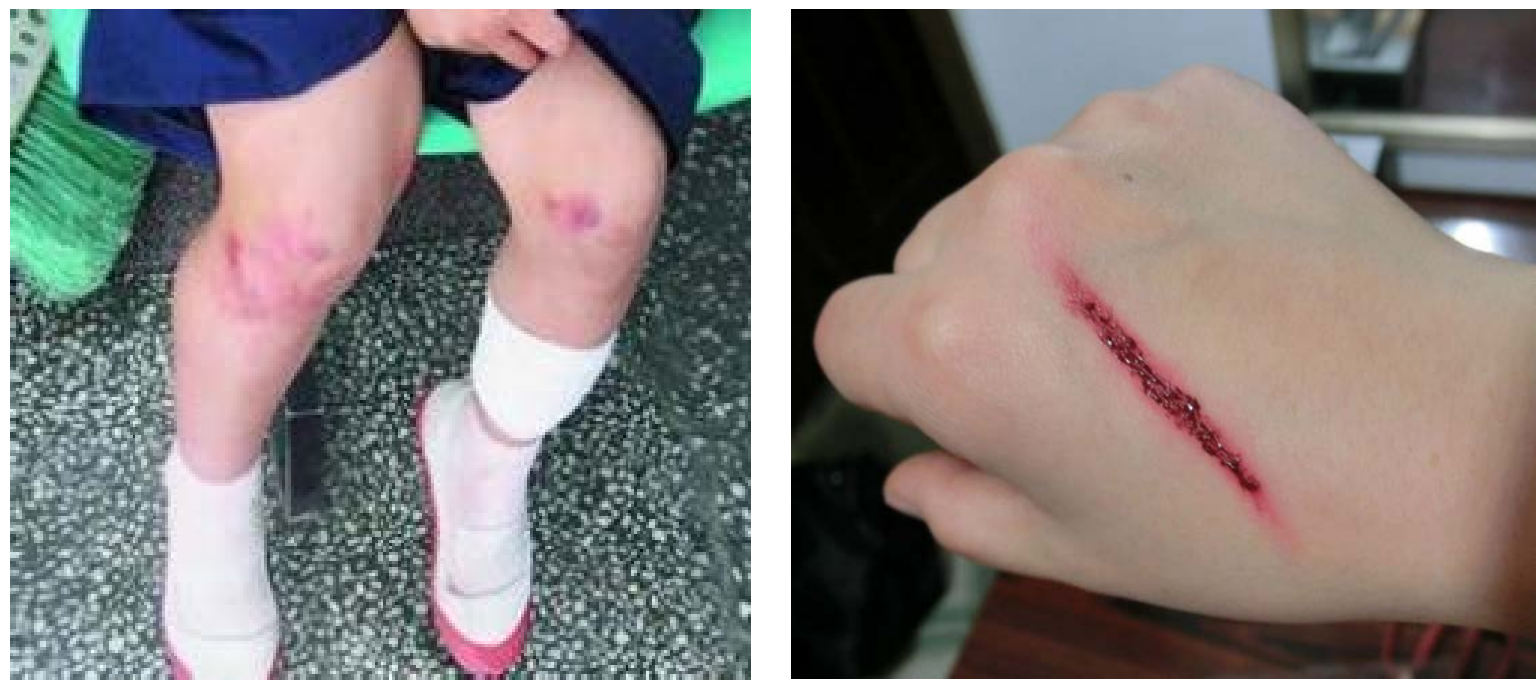

Fig. 4 The wound in the daily sports and fitness

The most common infective bacteria are such gram-positive bacteria as Staphylococcus aureus (Fig 5 A), Streptococcus pneumoniae, Streptococcus pyogenes and such Gram-negative as Escherichia coli, Haemophilus influenzae (Fig 5 B). In vivo infection by pathogenic microorganisms will cause acute systemic infection, especially for the children, the elderly, immunocompromised or with chronic diseases, and without timely treatment there will be some complications and even sepsis or sepsis. 


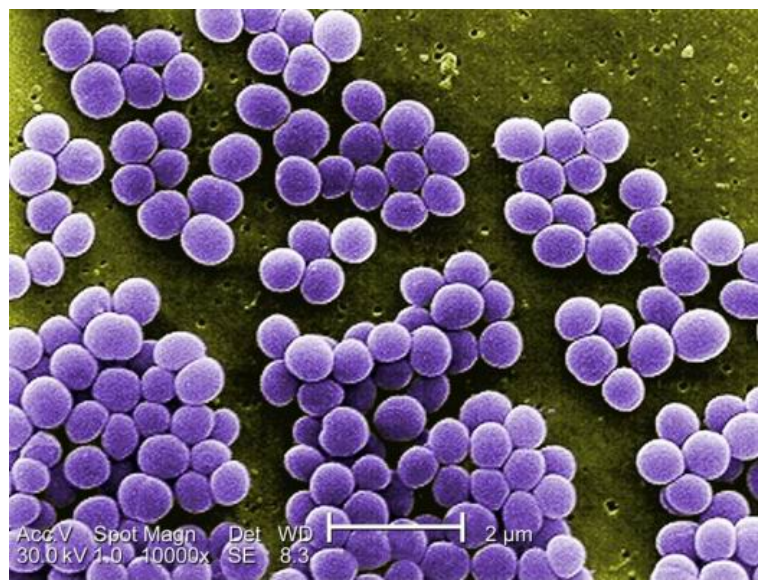

(A)

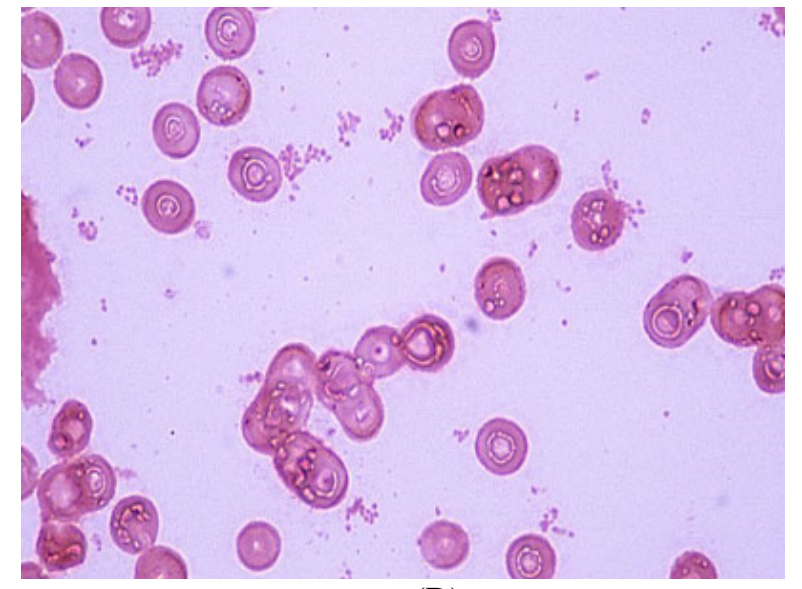

(B)

Fig. 5 The photograph of Staphylococcus aureus and Haemophilus influenzae

In this work, we investigated the anti-inflammatory activity of the title compound under the concentration of $20 \mathrm{mg} / \mathrm{L}$ and $200 \mathrm{mg} / \mathrm{L}$. and the results were summarized in Table 2 . From the results, it was found that the title compound shows some anti-inflammatory activity against the tested bacteria and the inhibition is depending on the concentration. The title compound are more active against $S$. aureus, $S$. epidermidis, and $E$. coli under both concentration with the inhibition effect more than $50 \%$ under $20 \mathrm{mg} / \mathrm{L}$ and the highest inhibition effect of $88.6 \%$ under $200 \mathrm{mg} / \mathrm{L}$ against $S$. epidermidis. But it is not so active against other three bacteria, M. luteus, K. pneumoniae, and A. fumigatus, with much lower inhibition effects.

Table 2 The anti-inflammatory activity of the title compound

\begin{tabular}{ccccccc}
\hline Bacteria & S. aureus & S. epidermidis & M. luteus & E. coli & K. pneumoniae & A. fumigatus \\
\hline $\begin{array}{c}\text { Inhibition effect /\% } \\
\begin{array}{c}(20 \mathrm{mg} / \mathrm{L}) \\
\text { Inhibition effect /\% } \\
(200 \mathrm{mg} / \mathrm{L})\end{array}\end{array}$ & 56.8 & 85.1 & 45.2 & 77.8 & 39.2 & 45.3 \\
\hline
\end{tabular}

\section{Experimental}

\section{Materials}

All chemicals were purchased from Xi'an Chemical Companies. All yields refer to isolated products. The NMR spectrum was recorded on a Bruker Drx-400 spectrometer, operating at $400 \mathrm{MHz}$ for ${ }^{1} \mathrm{H} ; \delta$ values are reported in ppm and $J$ values in hertz, and the mass spectrum were recorded on a Micromass Platform $\mathbb{I}$ spectrometer, using the direct-inlet system operation with the electron impact (EI) mode at $75 \mathrm{eV}$.

\section{Synthesis of Cyclohexanone Pentaerythritol Ketal}

Cyclohexanone and pentaerythritol were added in a flask with the molar ratio of 2:1, and the toluene was added as the water carrier and the solvent. $5 \%$ (wt) solid acid, $\mathrm{NaHSO}_{4}$ was added as catalyst. The mixture was refluxed until no water can be carried out, and the mixture was cooled to room temperature. Then $\mathrm{NaHSO}_{4}$ was filtrated, and the toluene was evaporated out to produce crude product. Colorless crystals of cyclohexanone pentaerythritol ketal were obtained in ethanol by recrystallization with the yield of $75.9 \%, \mathrm{mp} 115.5-116.2^{\circ} \mathrm{C} ;{ }^{1} \mathrm{H}-\mathrm{NMR}\left(\mathrm{D}_{6}-\mathrm{DMSO}, 400 \mathrm{MHz}\right), \delta$ : 3.62 (4H, s), 1.76 (4H, t, $J=7.2 \mathrm{~Hz}), 1.55$ (4H, td, $J=7.6,1.2 \mathrm{~Hz}), 1.35$ (2H, t, $J=7.6 \mathrm{~Hz})$; MS (EI) $\mathrm{m} / \mathrm{z}: 296\left(\mathrm{M}^{+}\right)$. 


\section{X-ray Data Collection and Structure Refinement}

All $\mathrm{H}$ atoms were positioned geometrically, with $\mathrm{C}-\mathrm{H}=0.93-0.98 \AA$, and refined with a riding model, with $\operatorname{Uiso}(\mathrm{H})=1.2 U$ eq(carrier). Data collection: SMART; cell refinement: SAINT; data reduction: SAINT; program (s) used to solve structure: SHELXS97; program (s) used to refine structure: SHELXL97; molecular graphics: Ortep-3 for Windows; software used to prepare material for publication: WinGX.

\section{Thermal Analysis}

Thermal analysis was performed on a TGA/SDTA851e Thermal Analyzer, where the heating rate was $10 \mathrm{~K} \mathrm{~min}^{-1}$ in the range of 298-773 K.

\section{References}

[1] D. M. Clode: Chemical Reviews, Vol. 79 (1979), p. 491.

[2] J. J. Brown, R. H. Lenhard, S. Berstein: J. Am. Chem. Soc. Vol. 86 (1964), p. 2183.

[3] K. Bruns, J. Conrad, A. Steigel: Tetrahedron Vol. 35 (1979), p. 2523.

[4] M. J. Climent, A. Velty, A. Corma: Green Chemistry Vol. 4 (2002), p. 565.

[5] D. M. Clode: Chemical Reviews Vol. 79 (1979), p. 491.

[6] S. Chandan, H. Malik: Organic Letters Vol. 7 (2005), p. 5673.

[7] D. M. Clode: Chemical Reviews, 79 (1979), p. 491.

[8] S. V. Ley, H. W. M. Priepke: Angew. Chem. Inter. Ed. Vol. 106 (1994), p. 2412.

[9] M. K. Cheung, N. L. Douglas, B. Hinzen, S. V. Ley: Synlett, Vol. 3 (1997), p. 257.

[10] K. Narasaka, M. Inone, T. Yamada, J. Sugiomori: Chem. Lett. Vol. 16 (1987), p. 2409.

[11] A.O. Barros, A.T. Faisca, E.R. Latcher, R. Nascimento: J. Bra. Chem. Soc. Vol. 22 (2011), p. 359.

[12] F. P. Tarun, N. W. Bina, V. C. Uma: Ind. Eng. Chem. Res. Vol. 52 (2013), p. 8969. 